CAHIERS DE

NARRATOLOGIE

\section{Cahiers de Narratologie}

Analyse et théorie narratives

22 | 2012

Voix off et narration cinématographique. Second volet

\title{
Propos introductifs
}

Voix-off et narration cinématographique - second volet

\section{Christel Taillibert}

\author{
(2) OpenEdition \\ Journals \\ Édition électronique \\ URL : http://journals.openedition.org/narratologie/6567 \\ DOI : $10.4000 /$ narratologie.6567 \\ ISSN : 1765-307X \\ Éditeur \\ LIRCES \\ Référence électronique \\ Christel Taillibert, "Propos introductifs », Cahiers de Narratologie [En ligne], 22 | 2012, mis en ligne le 20 \\ juillet 2012, consulté le 19 avril 2019. URL : http://journals.openedition.org/narratologie/6567 ; DOI : \\ $10.4000 /$ narratologie.6567
}

Ce document a été généré automatiquement le 19 avril 2019

Article L.111-1 du Code de la propriété intellectuelle. 


\title{
Propos introductifs
}

\author{
Voix-off et narration cinématographique - second volet
}

\section{Christel Taillibert}

1 En juillet dernier, un précédent numéro des Cahiers de narratologie proposait une première étude consacrée à la voix-off dans ses relations avec la narration cinématographique ( http://narratologie.revues.org/6292). Ce numéro retraçait les interventions de différents chercheurs lors des deux premières journées d'études consacrées à cette question par le LIRCES (Laboratoire interdisciplinaire Récits, Culture Et Sociétés), laboratoire de la faculté des Lettres, Arts et Sciences Humaines de l'Université Nice-Sophia Antipolis. Une troisième journée d'études fut consacrée à cette question le 13 octobre 2011, laquelle offrit la possibilité d'approfondir la réflexion préalablement entamée, à travers de nouvelles approches dont rendra compte le présent numéro.

2 Appliquée à la narratologie, l'analyse de la voix-off au cinéma rencontre immédiatement la question de sa fonction dans le processus de communication mis en œuvre par le cinéaste. Parfois, cette fonction est clairement identifiée, quand bien même elle arbore des visages très divers. C'est le cas par exemple de la voix off mise au service de l'effroi. Comme le démontre Martin Barnier à travers son travail historique, le cinéma n'a jamais négligé le pouvoir de la voix-off dans la création d'une atmosphère lugubre, d'un climat angoissant, d'une tension chez le spectateur, utilisant l'expérience acquise de longue date dans les spectacles de lanterne magique, les théâtres d'ombres, les fantasmagories dont raffolaient les spectateurs du XVIIIe et du XIXe siècle. La voix off serait donc, dans chaque projet singulier, porteur d'une fonction spécifique au regard du projet artistique développé par le cinéaste.

3 L'article de Paola Palma, consacré au rôle joué par la voix-off dans les processus d'adaptation en œuvre dans deux films de Louis Malle (Ascenseur pour l'échafaud et le Feu Follet), est particulièrement significatif quant aux besoins auxquels répond, concrètement, le recours à cet artifice : travaillant à la fois sur les romans dont sont issus les deux films, sur les différentes étapes de l'écriture scénaristique, et sur le film luimême, l'auteur analyse en effet de façon extrêmement probante les différentes réflexions qui prévalent dans le choix de ce procédé cinématographique au cours d'un travail d'adaptation. Paola Palma montre bien à travers quel cheminement, cherchant à éviter le 
recours à une simple voix narrative qui se contenterait d'opérer une transposition mécanique du rôle du narrateur en littérature, Malle a travaillé ses recours à la voix-off afin de transmettre - presqu'insidieusement - au spectateur les informations et l'atmosphère voulue dans chacun de ces deux films. Elle montre par exemple comment, dans Ascenseur pour l'échafaud, Julien, qui pour des raisons scénaristiquement évidentes est pratiquement absent à l'image, physiquement parlant, prend de l'épaisseur, au fur et à mesure que le film avance, grâce à la voix-off qui retrace les pensées de Florence, sa maîtresse, en proie à l'angoisse de l'incertitude.

4 La capacité de la voix-off à offrir un contrepoint à l'absence physique d'un personnage est aussi une idée fondamentale de The Man Who Envied Women, film d'Yvonne Rainer dont Johanna Renard offre ici une analyse. L'absence du corps de son héroïne - la danseuse et chorégraphe Tricha Brown - à l'écran répond pour la cinéaste à un objectif idéologique : dénoncer l'instrumentalisation dont est l'objet le corps féminin au cinéma. C'est donc à travers le verbe que ce personnage se construit au fur et à mesure que le film se déroule, en l'absence d'ailleurs de toute architecture scénaristique classique. La voix (off) du film offre ici un champ privilégié à la confession, à l'introspection, invitant le spectateur à interroger l'espace de sa propre intimité.

5 Cette idée d'une voix-off utilisée comme outil privilégié de l'introspection est très présente dans les différents textes de ce numéro. On la retrouve dans le travail de MarieAnne Lieb sur l'œuvre filmique d'Arnaud Desplechin. Chez ce cinéaste en effet, les récits tendent à ouvrir et à interroger l'espace de la conscience, la voix-off offrant une expression sensible des remous de l'âme. L'exercice est souvent l'occasion d'une évolution, d'une remise en cause, d'une démarche salvatrice pour les personnages torturés qu'anime Desplechin dans ses différents opus. On retrouve ce travail introspectif, selon des tonalités différentes, dans l'œuvre d'Isabel Coixet, qu'étudie ici Silvina Bénévent Gonzàles. Dans les trois films analysés, la voix-off utilisée de façon récurrente mobilise un passé obscur, tisse des liens avec les disparus, convoque l'intimité. Pour les personnages de ces fictions confrontés à des traumatismes, la voix-off, offrant une scène à la confession, constitue là encore un instrument cathartique.

Le champ d'investigation de la voix-off au service de la narration cinématographique est bien entendu infini. Les deux numéros que les Cahiers de narratologie ont consacrés à cette question permettent cependant d'en appréhender quelques facettes marquantes des cinématographies d'hier et d'aujourd'hui. 